Universidade Tecnológica Federal do Paraná - UTFPR

Campus Ponta Grossa - Paraná - Brasil

ISSN: 1981-3686/ v. 9, n. 2: p. 1932-1944, 2015

D.O.I.: http://dx.doi.org/10.3895/rbta.v9n2.1870
Revista Brasileira deTecnologia

Agroindustrial

\title{
ANÁLISES FÍSICO-QUÍMICAS E LEGISLAÇÃO BRASILEIRA DE POLPAS, SUCOS TROPICAIS E NÉCTARES DE MANGA
}

\section{PHYSICAL-CHEMICAL ANALYSIS AND BRAZILIAN LEGISLATION OF MANGO PULP, TROPICAL JUICES AND NECTARS}

\author{
Andressa Milene Parente Nogueira ${ }^{1}$, Vitor Massami Imaizumi ${ }^{1}$, \\ Ricardo Figueira ${ }^{1}$, Waldemar Gastoni Venturini Filho ${ }^{1}$

\begin{abstract}
${ }^{1}$ Faculdade de Ciências Agronômicas, Universidade Estadual Paulista- São Paulo- Brasil
\end{abstract} \\ vtr_massami@hotmail.com; andressa_nogueira@yahoo.com.br; ricardofigueira@hotmail.com; \\ venturini@fca.unesp.br;
}

\begin{abstract}
Resumo
O objetivo deste trabalho foi realizar análises físico-químicas em polpas, sucos tropicais e néctares de manga para compará-los quanto à sua adequação aos Padrões de Identidade e Qualidade (PIQ) estabelecidos pelo Ministério da Agricultura, Pecuária e Abastecimento (MAPA). Seis amostras de polpas, sete de sucos tropicais (quatro não adoçados e três adoçados) e nove de néctares (seis convencionais e três light) foram analisadas quanto ao teor de sólidos solúveis ( ${ }^{\circ}$ Brix), pH, acidez totale açúcares totais. Seguindo-se os parâmetros determinados por lei, as polpas também foram analisadas para concentração de sólidos totais, além do ratio. Dentre as bebidas, todas as marcas de sucos tropicais e néctares apresentaram resultados condizentes com a legislação em vigor. No entanto, o mesmo não ocorreu com as polpas, sendo que uma amostra apresentou valor de açúcares totais acima do máximo permitido, enquanto que outras duas apresentaram valores de sólidos totais abaixo do mínimo. Dentre vinte e duas amostras analisadas, três não atenderam as exigências da legislação brasileira. Isso mostra que a inadequação dos produtos de manga foi restrita a casos pontuais, representando, no presente estudo, 14\%das amostras analisadas.
\end{abstract}

Palavras-chave: Mangifera indica; análise físico-química; padrões de identidade e qualidade.

\section{INTRODUÇÃO}

A manga é originária da Ásia e é uma das mais importantes frutas tropicais. Os portugueses, que deram nome à fruta, foram responsáveis por sua introdução no Ocidente, plantando-a no Brasil por volta de 1700 (MANGO, 2011). 
De acordo com a Organização das Nações Unidas para Agricultura e Alimentação (FAO, 2014), que contabilizou os dados de manga (Mangifera indica, L.), goiaba (Psidium guajava, L.)e mangostão (Garcinia mangostana, L.) juntos, o mundo produziu em 2012 quase 42,2 milhões de toneladas das três frutas tropicais. Todavia, a manga é, certamente, a mais importante das três fruteiras.

A Índia, o maior produtor mundial, é responsável por praticamente $36 \%$ do total, com uma produção quase quatro vezes maior que a China, a segunda colocada no ranking. O Brasil ocupa a oitava posição nessa classificação, participando com 2,8\% (FAO, 2014).

Em 2012, o Brasil colheu aproximadamente 1,18 milhão de toneladas de manga (Instituto Brasileiro de Geografia e Estatística - IBGE, 2014). A maior parte da produção está localizada nas regiões Nordeste e Sudeste, com participação de 66,5 e 32,1\%, respectivamente. O grande destaque é o Estado da Bahia, com praticamente 35,9\% da produção total, seguido de São Paulo, com 19,9\% (IBGE, 2014)

O consumo de manga in natura é, sem dúvida, predominante (MAGALHÃES et al., 2008)em relação à fruta processada industrialmente. No entanto, sua industrialização é uma excelente alternativa para a manutenção de seus atributos de qualidade, podendo ser processada na forma de polpas, sucos, néctares, desidratados, entre outros (OLIVEIRA, 2006).

Nos últimos anos, as vendas de frutas processadas na forma de polpas, sucos e néctares vêm aumentando significativamente no mercado brasileiro devido à melhoria da qualidade dos produtos ofertados, praticidade de consumo, aumento de renda da população, elevado valor nutritivo, bem como a preocupação dos consumidores em adquirir alimentos mais saudáveis.

No entanto, a fiscalização no segmento de bebidas é muito importante para garantir à população produtos de qualidade certificada. O conhecimento da composição físico-química de polpas, sucos e néctares comerciais faz-se necessário para compará-la com os parâmetros propostos pelo MAPA. No Brasil, o controle de qualidade de bebidas a base de frutas é realizado tendo como referência os PIQ, definidos pelo MAPA, que indicam as características físicas, químicas e organolépticas, estabelecendo limites mínimos e máximos específicos para cada tipo de produto.

Dessa forma, a polpa de manga é definida como o produto não fermentado e não diluído, obtido da parte comestível da manga, através de processo tecnológico adequado, com teor mínimo de sólidos totais (BRASIL, 2000). O PIQ da polpa de manga estabelece concentração mínima de sólidos solúveis de $11^{\circ} \mathrm{Brix}$; pH mínimo de 3,3 e máximo de 4,5; acidez total mínima de 0,32g de ácido cítrico/100g; teores máximos de açúcares totais de $17 \mathrm{~g} / 100 \mathrm{~g}$ e mínimo de sólidos totais de $14 \mathrm{~g} / 100 \mathrm{~g}$ de polpa (BRASIL, 2000).

Suco tropical de manga é a bebida não fermentada, obtida pela dissolução, em água potável, da polpa da manga (BRASIL, 2003). Os teores de polpa de frutas utilizados na elaboração do suco 
tropical deverão ser superiores aos estabelecidos para o néctar das respectivas frutas (BRASIL, 2009). Quando adicionado de açúcar, o suco tropical deverá ser denominado suco tropical, acrescido do nome da fruta e da designação adoçado, podendo ser declarado no rótulo a expressão suco pronto para beber, pronto para o consumo ou expressões semelhantes (BRASIL 2009). É vedada a designação de "suco tropical" a bebida que não necessite de água na sua elaboração e que não seja proveniente de fruta de origem tropical (BRASIL, 2003).

O suco tropical não adoçado de manga deve conter, no mínimo, 60\% de polpa na sua formulação; teor mínimo de sólidos solúveis de $10^{\circ}$ Brix; acidez total mínima de $0,30 \mathrm{~g}$ de ácido cítrico/100g e açúcares totais máximos de 14g/100g de suco (BRASIL, 2003). O adoçado deve conter, no mínimo, 50\% de polpa; $11^{\circ}$ Brix; 0,20g de ácido cítrico/100g e $8 \mathrm{~g}$ de açúcares totais/100g de suco (BRASIL, 2003).

Néctar de manga é a bebida não fermentada, obtida da dissolução, em água potável, da parte comestível da manga e açúcares, destinado ao consumo direto, podendo ser adicionado de ácidos (BRASIL, 2003). O PIQ para néctar de manga estabelece mínimo de $40 \%$ de polpa; teor de sólidos solúveis maior ou igual a $10^{\circ}$ Brix; acidez mínima de $0,20 \mathrm{~g}$ de ácido cítrico/100g e $7 \mathrm{~g}$ de açúcares totais/100g de néctar (BRASIL, 2003).

Bebida de baixa caloria (light) é a bebida não-alcoólica, hipocalórica, que tenha o conteúdo de açúcares adicionado normalmente na bebida convencional inteiramente substituído por edulcorante hipocalórico ou não-calórico, natural ou artificial, em conjunto ou separadamente (BRASIL, 2009).

Com base nessas informações, o objetivo deste trabalho foi realizar análises físico-químicas em polpas, sucos tropicais e néctares de manga de diferentes marcas comercializadas no mercado brasileiro e compará-las quanto à sua adequação aos PIQ estabelecidos pelo MAPA.

\section{MATERIAL E MÉTODOS}

\section{Amostras}

Quatro amostras de polpas de manga foram doadas por diferentes indústrias produtoras de sucos e néctares de frutas. Outras duas foram compradas em supermercados de cidade do interior do estado de São Paulo, assim como quatro marcas de sucos tropicais não adoçados, três adoçados, seis néctares convencionais e três light de manga. Todos os produtos foram adquiridos em triplicata (cada embalagem representando uma repetição), com o mesmo número de lote, dentro do prazo de validade e mantidos a temperatura ambiente, em suas embalagens originais, até a realização das análises.

As amostras foram identificadas com diferentes números para ocultar a identidade de seus 
fabricantes.

\section{Análises físico-químicas}

Antes das análises, os produtos foram homogeneizados. Em seguida, os mesmos foram analisados para teor de sólidos solúveis ( $\left.{ }^{\circ} \mathrm{Brix}\right), \mathrm{pH}$, acidez total e açúcares totais. Seguindo-se os parâmetros determinados por lei, as polpas também foram analisadas para concentração de sólidos totais, além do ratio.

\section{Sólidos solúveis em ${ }^{\circ}$ Brix (SS)}

As amostras foram injetadas diretamente em densímetro digital (Mettler; modelo KEM DA310) para a leitura de densidade $\left(\mathrm{D}_{20 / 20}\right)$. $\mathrm{O}$ valor da densidade foi convertido para ${ }^{\circ} \mathrm{Brix}$ através do uso de tabela específica.

\section{Potencial hidrogeniônico $(p H)$}

A leitura do $\mathrm{pH}$ foi realizada em peagâmetro digital (Micronal; modelo B474), calibrado com soluções tampão de pH 4,0 e 7,0.

\section{Acidez total em ácido cítrico (AT)}

A determinação da acidez total foi realizada segundo a técnica descrita por Brasil (2005), por titulometria. Foram pesados $10 \mathrm{~g}$ de amostra em um béquer de $250 \mathrm{~mL}$ e adicionados $50 \mathrm{~mL}$ de água deionizada. Esta solução foi colocada em peagâmetro e mantida sob agitação enquanto procedeu-se a titulação com hidróxido de sódio $(\mathrm{NaOH})$ 0,1N até pH 8,2 - 8,4. Os resultados foram obtidos a partir da Equação 1 e expressos em g de ácido cítrico/100g de amostra.

$$
\mathrm{AT}=\frac{\mathrm{N} * \mathrm{~V} * 64}{\mathrm{~A} * 1000} * 100
$$

Sendo: $\mathrm{N}$ = normalidade da solução de $\mathrm{NaOH}(0,1 \mathrm{~N})$;

$\mathrm{V}=$ volume médio de $\mathrm{NaOH}$ gasto na titulação em $\mathrm{mL}$;

64 = número de equivalente grama do ácido cítrico $\left(\mathrm{C}_{6} \mathrm{H}_{8} \mathrm{O}_{7}\right)$;

$\mathrm{A}=$ massa de amostra em grama.

\section{Ratio}

Relação entre ${ }^{\circ}$ Brix e acidez total (Equação 2). Os resultados desta análise são adimensionais. 


$$
\text { Ratio }=\frac{{ }^{\circ} \text { Brix }}{\text { Acidez total }}
$$

\section{Açúcares totais (AçT)}

Soma dos açúcares redutores em glicose e dos açúcares não redutores em sacarose. Os resultados foram obtidos por meio da Equação 3 e expressos em g de açúcares totais/100g de amostra.

$$
\mathrm{AçT}=\mathrm{AR} \text { em glicose }+\mathrm{ANR} \text { em sacarose }
$$

Sendo: $\mathrm{AR}=$ açúcares redutores;

$\mathrm{ANR}=$ açúcares não redutores.

A quantificação de AR foi obtida por método titulométrico baseado na redução de cobre pelos grupos redutores dos açúcares, segundo Eynon Lane, utilizando solução de Fehling (COPERSUCAR, 1978). Os resultados foram obtidos por meio da Equação 4 e expressos em g de glicose/100g de amostra.

$$
\mathrm{AR}=\frac{\mathrm{T} * \mathrm{D} * 1000}{\mathrm{~V}}
$$

Sendo: $\mathrm{T}$ = título do licor de Fehling;

$\mathrm{D}$ = fator de diluição da amostra;

$\mathrm{V}=$ volume médio de amostra gasta na titulação em $\mathrm{mL}$.

O ANR foi obtido pela Equação 5:

$$
\mathrm{ANR}=(\text { ART em glicose }- \text { AR em glicose }) * 0,95
$$

Sendo: $\mathrm{ART}=$ açúcares redutores totais.

Para determinar o valor de ART, foi utilizado o mesmo método titulométrico que para o AR (COPERSUCAR, 1978), porém com hidrólise ácida da amostra a $60^{\circ} \mathrm{C}$. Os resultados foram obtidos pela Equação 6 e expressos em g de glicose/100g de amostra.

$$
\mathrm{ART}=\frac{\mathrm{T} * \mathrm{D} * 1000}{\mathrm{~V}}
$$

Sendo: $\mathrm{T}$ = título do licor de Fehling; 
$\mathrm{D}$ = fator de diluição da amostra;

$\mathrm{V}=$ volume médio de amostra gasta na titulação em $\mathrm{mL}$.

\section{Sólidos totais $(S T)$}

Para determinar os sólidos totais seguiu-se a metodologia proposta por Brasil (2005). Pesouse analiticamente cerca de $5 \mathrm{~g}$ de amostra em cápsula de porcelana previamente aquecida a $105^{\circ} \mathrm{C}$ por 2 horas, resfriada em dissecador até a temperatura ambiente e pesada. A cápsula contendo a amostra foi levada ao banho-maria fervente para evaporar lentamente até a secura. Em seguida, a mesma foi colocada em estufa a $105^{\circ} \mathrm{C}$ por 2 horas, resfriada em dissecador e pesada. As operações de aquecimento por 30 minutos e resfriamento foram repetidas até peso constante. Os resultados foram obtidos conforme a Equação 7 e expressos em g de resíduo seco/100g de amostra.

$$
\mathrm{ST}=\frac{100 * \mathrm{~N}}{\mathrm{~A}}
$$

Sendo: $\mathrm{N}$ = número de grama de resíduo seco;

$\mathrm{A}=$ número de grama da amostra.

\section{Análise estatística}

As comparações estatísticas foram realizadas entre suco tropical não adoçado vs. adoçado e néctar convencional vs. light para uma mesma variável (teor de sólidos solúveis, $\mathrm{pH}$, acidez total e açúcares totais) utilizando o programa ASSISTAT (SILVA; AZEVEDO, 2009), pelo Teste $t$, com nível de significância igual a 5\%.

\section{RESULTADOS E DISCUSSÃO}

Nas polpas de manga, todos os parâmetros analisados apresentaram altos coeficientes de variação, com exceção do pH (Tabela 1). Segundo Chitarra e Chitarra (1990), a capacidade reguladora de alguns derivados de frutos pode levar a grande variação na acidez total, sem que isto afete grandemente o $\mathrm{pH}$. Os altos coeficientes de variação se devem, principalmente, aos valores discrepantes obtidos para a amostra 3. De acordo com a embalagem deste produto, tratava-se de uma polpa concentrada, o que explica os valores mais elevados em relação aos demais produtos. Todavia, de acordo com Brasil (2009), as polpas de fruta não podem ser concentradas. 
Além disso, a composição química das frutas pode variar em função dos tratos culturais, variedade, condições climáticas, do estágio de maturação dos frutos, entre outros fatores (CARDELLO; CARDELLO, 1998; PINHEIRO et al., 2006).

Apesar dessa variação, as concentrações de sólidos solúveis ( ${ }^{\circ}$ Brix) das polpas analisadas condizem com a legislação brasileira (Tabela 1).

Branco e Gasparetto (2005), ao caracterizarem físico-quimicamente polpa de manga proveniente da variedade 'Haden', obtiveram valor de $17^{\circ}$ Brix. Pontes (2008) publicou os resultados de análises físico-químicas de várias variedades de mangas cultivadas no Brasil, obtidos por diferentes autores. Esses autores observaram que os sólidos solúveis variaram entre 14,1 a $19,0^{\circ}$ Brix. O valor médio de sólidos solúveis obtido no presente estudo $\left(16,03^{\circ}\right.$ Brix $)$ foi menor em relação ao obtido por Branco e Gasparetto (2005), mas dentro do intervalo apresentado por Pontes (2008). Essas pesquisas evidenciam, mais uma vez, a grande variabilidade neste tipo de produto.

Todas as amostras de polpa atenderam aos valores de $\mathrm{pH}$ (Tabela 1)determinados por lei. Segundo Silva et al. (2005), o pH é de suma importância,visto que acima de 4,5pode favorecer o crescimento do Clostridium botulinum em determinados produtos alimentícios.

Quanto à acidez total, todas as amostras estavam de acordo com a legislação brasileira (Tabela 1). A determinação de acidez pode fornecer um dado valioso na apreciação do estado de conservação de um produto alimentício. Um processo de decomposição, seja por hidrólise, oxidação ou fermentação, altera, quase sempre, a concentração dos íons de hidrogênio (BRASIL, 2005).

O ratio é uma das melhores formas de avaliação do sabor, sendo mais representativo que a medição isolada de açúcares ou da acidez. Com ela, tem-se uma boa idéia do equilíbrio entre esses dois componentes, porém, deve-se especificar o teor mínimo de sólidos e o máximo de acidez (CHITARRA; CHITARRA, 1990), mas a legislação brasileira menciona apenas o teor mínimo desses dois parâmetros.

Ainda, observando-se os resultados da Tabela 1, foi possível notar que a amostra 3 extrapolou o teor máximo de açúcares totais permitido por lei. Enquanto a legislação brasileira previa máximo de 17\% (BRASIL, 2003), essa amostra apresentou valor de 22,45\%. Conforme mencionado anteriormente, a amostra 3 é uma polpa concentrada, o que explica este fato.

Em relação ao teor de sólidos totais, as amostras 99 e 100 apresentaram valores(13,09 e $12,50 \%$, respectivamente) abaixo do mínimo exigido pelas normas do MAPA que preconiza mínimo de 14\% (BRASIL, 2000). 
Tabela 1 - Análises físico-químicas das polpas de manga.

\begin{tabular}{|c|c|c|c|c|c|c|}
\hline $\mathbf{N}^{\circ}$ & $\begin{array}{c}\text { SS } \\
\left({ }^{\circ} \text { Brix }\right) \\
\end{array}$ & pH & $\begin{array}{c}\mathrm{AT} \\
(\mathrm{g} / \mathbf{1 0 0 g}) \\
\end{array}$ & Ratio & AçT (g/100g) & $\begin{array}{c}\text { ST } \\
(\mathrm{g} / \mathbf{1 0 0 g})\end{array}$ \\
\hline 2 & 14,40 & 3,97 & 0,48 & 29,8 & 9,62 & 14,29 \\
\hline 3 & 28,00 & 3,91 & 0,69 & 40,6 & 22,45 & 28,56 \\
\hline 60 & 15,30 & 4,02 & 0,42 & 36,4 & 10,69 & 15,53 \\
\hline 82 & 14,40 & 4,26 & 0,32 & 43,6 & 11,16 & 14,87 \\
\hline 99 & 12,30 & 3,91 & 0,56 & 22,0 & 9,26 & 13,09 \\
\hline 100 & 11,80 & 4,13 & 0,37 & 31,9 & 8,34 & 12,50 \\
\hline Média & 16,03 & 4,03 & 0,47 & 34,1 & 11,92 & 16,47 \\
\hline Desvio padrão & 6,02 & 0,14 & 0,14 & 7,84 & 5,26 & 6,03 \\
\hline $\begin{array}{l}\text { Coeficiente de variação } \\
(\%)\end{array}$ & 37,52 & 3,42 & 28,58 & 23,03 & 44,10 & 36,58 \\
\hline $\mathbf{P I Q}^{1}$ & mín. 11,0 & $\begin{array}{l}\text { mín. } 3,3 \\
\text { máx. } 4,5\end{array}$ & mín. 0,32 & - & máx. 17,0 & mín. 14,0 \\
\hline
\end{tabular}

FONTE: Brasil (2000).

Os sucos tropicais de manga são fundamentalmente constituídos por polpa, água, aditivos e, no caso dos adoçados, açúcares. Como discutido anteriormente, é comum a polpa apresentar variações em sua composição química, o que refletirá no produto final. Além disso, cada empresa possui sua própria formulação, variando as quantidades de sacarose, água e aditivos.

Apesar disso, tanto o suco tropical não adoçado como o adoçado apresentaram teores de sólidos solúveis (Tabela 2) acima do mínimo determinado pela legislação brasileira. Embora os sucos tropicais adoçados sejam acrescidos de açúcar, prática que deveria elevar suas concentrações de sólidos solúveis quando comparados aos sucos não adoçados, não foi encontrada diferença estatística entre esses dois tipos de bebidas. Isso pode ter ocorrido pela variabilidade de resultados obtidos em diferentes marcas comerciais analisadas.

Por outro lado, ao comparar as médias de açúcares totais dos sucos tropicais não adoçados e adoçados, pode-se constatar diferença entre ambos (Tabela 2), conforme o esperado. Em relação a esse parâmetro, todas as bebidas enquadraram-se na legislação.

$\mathrm{O}$ pH, apesar de ser um parâmetro importante na análise de produtos alimentícios, tais como influência na palatabilidade, desenvolvimento de microrganismo, equipamento para o processamento, entre outros (CHAVES, 1993), não é aludido pelo PIQ para sucos tropicais de manga. Dessa forma, recorreu-se a literatura para comparar os resultados deste trabalho. Santos et al. (2005), ao analisarem parâmetros físico-químicos de sucos tropicais de manga de diferentes marcas comerciais brasileiras, obtiveram valores de $\mathrm{pH}$ na faixa de 2,97 a 3,89. As médias dos resultados para os sucos tropicais não adoçados e adoçados (3,37 e 3,77, respectivamente), apresentadas na Tabela 2, estão inseridas no intervalo obtido por Santos et al. (2005).

A legislação brasileira estabelece o valor mínimo de $0,30 \mathrm{~g}$ de ácido cítrico/100g para os sucos tropicais não adoçados de manga (BRASIL, 2003). Ainda que a média obtida no presente 
estudo esteja dentro do valor permitido, o resultado foi muito superior ao esperado $(0,80 \mathrm{~g}$ de ácido cítrico/100g - Tabela 2). Lembrando que o suco tropical não adoçado é composto basicamente por polpa, água e aditivos, era esperado que o produto tivesse seu teor de acidez próximo ao da polpa utilizada em sua formulação ou mesmo inferior. Como observado anteriormente, as polpas do presente estudo tiveram média de $0,5 \mathrm{~g}$ de ácido cítrico/100g. No entanto, as empresas utilizam acidulante (ácido cítrico) na formulação dessas bebidas, aumentando, conseqüentemente, a acidez do produto final. Além disso, conforme consta nos rótulos desses produtos, os mesmos devem ser diluídos para o consumo, fazendo com que as indústrias, provavelmente, adicionem quantidades mais expressivas do aditivo. Isso também explica a diferença estatística entre os sucos tropicais não adoçados e adoçados (Tabela 2). Nos sucos tropicais adoçados, a própria adição de açúcar resulta em queda nos valores de acidez total, além do controle realizado pelas indústrias para garantir aos consumidores uma bebida mais ajustada ao paladar, uma vez que os mesmos tratam-se de produtos prontos para o consumo. Todas as marcas de sucos tropicais adoçados estavam de acordo com as normas do MAPA quanto à acidez total.

Com base na discussão acima e sabendo-se que o pH apresenta uma relação inversa com a acidez total, era esperado que os sucos tropicais não adoçados tivessem valores de pH menores e, portanto, mais ácidos, em relação aos adoçados, fato comprovado estatisticamente (Tabela 2).

Tabela 2 - Análises físico-químicas dos sucos tropicais de manga.

\begin{tabular}{|c|c|c|c|c|}
\hline $\mathbf{N}^{\circ}$ & $\begin{array}{l}\text { SS } \\
\left({ }^{\circ} \text { Brix) }\right.\end{array}$ & pH & $\begin{array}{l}\text { AT } \\
(\mathrm{g} / 100 \mathrm{~g})\end{array}$ & $\begin{array}{l}\text { Aç'T } \\
(\mathrm{g} / 100 \mathrm{~g})\end{array}$ \\
\hline \multicolumn{5}{|l|}{ Sucos tropicais não adoçados } \\
\hline 11 & 12,10 & 3,38 & 0,85 & 8,15 \\
\hline 12 & 11,40 & 3,34 & 0,71 & 7,65 \\
\hline 13 & 10,00 & 3,24 & 0,88 & 7,30 \\
\hline 97 & 11,60 & 3,52 & 0,76 & 8,66 \\
\hline Média & $11,28 \mathrm{a}^{2}$ & $3,37 \mathrm{a}$ & $0,80 \mathrm{a}$ & $7,94 \mathrm{a}$ \\
\hline Desvio padrão & 0,90 & 0,12 & 0,08 & 0,59 \\
\hline Coeficiente de variação (\%) & 7,98 & 3,44 & 9,84 & 14,41 \\
\hline $\mathbf{P I Q}^{1}$ & mín. 10,0 & - & mín. 0,30 & máx. 14,0 \\
\hline \multicolumn{5}{|l|}{ Sucos tropicais adoçados } \\
\hline 94 & 12,80 & 3,70 & 0,29 & 11,64 \\
\hline 95 & 11,50 & 3,93 & 0,21 & 9,44 \\
\hline 98 & 11,50 & 3,67 & 0,27 & 9,54 \\
\hline Média & $11,93 \mathrm{a}$ & $3,77 \mathrm{~b}$ & $0,26 b$ & $10,21 b$ \\
\hline Desvio padrão & 0,75 & 0,14 & 0,04 & 1,24 \\
\hline Coeficiente de variação $(\%)$ & 6,29 & 3,78 & 16,22 & 14,11 \\
\hline $\mathbf{P I Q}^{1}$ & mín. 11,0 & - & mín. 0,20 & mín. 8,0 \\
\hline
\end{tabular}

${ }^{1}$ Brasil (2003); ${ }^{2}$ comparação estatística entre suco tropical não adoçado vs. adoçado para uma mesma variável (teor de sólidos solúveis, $\mathrm{pH}$, acidez total e açúcares totais). Letras em comum não diferem estatisticamente (Teste $t, \alpha=0,05)$.

Os teores de sólidos solúveis encontrados nas diferentes marcas de néctares convencionais 
não variaram de maneira expressiva (Tabela 3). As pequenas diferenças podem ser explicadas pelo fato de cada indústria ter sua própria receita. Porém, todos os valores respeitaram o mínimo de $10^{\circ}$ Brix fixado pelo MAPA (Tabela 3).

Para os açúcares totais, todas as marcas de néctares convencionais estavam de acordo com lei (Tabela 3).

A legislação brasileira para bebidas de baixa caloria não menciona a concentração mínima de sólidos solúveis e açúcares totais que este tipo de bebida deve conter. Assim, não foi possível avaliar os néctares light de manga como sendo legais ou ilegais perante a lei, sob esses dois aspectos.

Estatisticamente, como era esperado, os teores de sólidos solúveis e açúcares totais dos néctares convencionais diferiram dos light (Tabela 3). Isso ocorreu porque, nos produtos light, o açúcar é totalmente substituído por edulcorantes naturais e/ou artificiais (BRASIL, 2009).

Tabela 3 - Análises físico-químicas dos néctares de manga.

\begin{tabular}{|c|c|c|c|c|}
\hline $\mathbf{N}^{\circ}$ & $\begin{array}{l}\text { SS } \\
\left({ }^{\circ} \text { Brix }\right)\end{array}$ & $\mathbf{p H}$ & $\begin{array}{l}\text { AT } \\
(\mathrm{g} / 100 \mathrm{~g})\end{array}$ & $\begin{array}{l}\text { AçT } \\
(\mathrm{g} / 100 \mathrm{~g})\end{array}$ \\
\hline \multicolumn{5}{|l|}{ Néctares convencionais } \\
\hline 4 & 14,50 & 3,43 & 0,34 & 11,99 \\
\hline 5 & 11,50 & 3,35 & 0,32 & 10,73 \\
\hline 6 & 12,40 & 3,32 & 0,31 & 10,44 \\
\hline 7 & 12,30 & 3,31 & 0,36 & 10,59 \\
\hline 8 & 12,40 & 3,10 & 0,35 & 10,79 \\
\hline 93 & 13,20 & 3,32 & 0,29 & 11,63 \\
\hline Média & $12,72 \mathrm{a}^{2}$ & $3,31 \mathrm{a}$ & $0,33 a$ & $11,03 \mathrm{a}$ \\
\hline Desvio padrão & 1,03 & 0,11 & 0,03 & 0,63 \\
\hline Coeficiente de variação (\%) & 8,07 & 3,32 & 8,04 & 5,69 \\
\hline $\mathbf{P I Q}^{1}$ & mín. 10,0 & - & mín. 0,20 & mín. 7,0 \\
\hline \multicolumn{5}{|l|}{ Néctares light } \\
\hline 9 & 4,20 & 3,24 & 0,35 & 3,30 \\
\hline 10 & 4,10 & 3,15 & 0,34 & 2,54 \\
\hline 96 & 4,80 & 4,10 & 0,23 & 3,31 \\
\hline Média & $4,37 \mathrm{~b}$ & $3,50 \mathrm{a}$ & $0,31 \mathrm{a}$ & $3,05 b$ \\
\hline Desvio padrão & 0,38 & 0,52 & 0,07 & 0,44 \\
\hline Coeficiente de variação (\%) & 8,67 & 15,00 & 21,71 & 34,07 \\
\hline $\mathbf{P I Q}^{1}$ & - & - & - & - \\
\hline
\end{tabular}

${ }^{1}$ Brasil (2003); ${ }^{2}$ comparação estatística entre néctar convencional vs. light para uma mesma variável (teor de sólidos solúveis, $\mathrm{pH}$, acidez total e açúcares totais). Letras em comum não diferem estatisticamente (Teste $t, \alpha=0,05)$.

Quanto ao pH dos néctares de manga, a lei também é omissa. Porém, Silva et al. (2005), ao analisar físico-quimicamente quatro marcas de néctares de manga comercializadas em Fortaleza/CE, encontraram valores variando entre 3,27 e 3,53. Conforme mostra a Tabela 3, as médias dos resultados para néctares convencionais e light $(3,31$ e 3,50, respectivamente) 
corresponderam aos dados encontrados por Silva et al. (2005).Não houve diferença estatística entre os dois tipos de bebidas.

Todos os néctares, tanto os convencionais como os light, enquadraram-se no valor mínimo de acidez total estabelecido pelas normas do MAPA (Tabela 3).

A acidez e, conseqüentemente o $\mathrm{pH}$ dessas bebidas, é corrigida pelas indústrias pelo uso de acidulantes, principalmente o ácido cítrico. Isso explica a pouca variação dos resultados entre as diferentes marcas analisadas, como também, a semelhança estatística ao comparar as bebidas convencionais e light para esses dois parâmetros (Tabela 3).

\title{
4 CONCLUSÃO
}

Das seis amostras de polpa de manga analisadas, metade estava em desacordo com as normas da legislação vigente.

Dentre as bebidas, todas as quatro marcas de sucos tropicais não adoçados, três adoçados, seis néctares convencionais e três light estavam em conformidade com a legislação brasileira.

A inadequação dos produtos de manga aos PIQ estabelecidos pelo MAPA foi restrita a casos pontuais, representando, no presente estudo, a 14\%das amostras analisadas.

\begin{abstract}
The objective of this work was to carry out physical-chemical analyses in mango pulps, tropical juices and nectars to compare them for suitability to the Identity and Quality Standards established by Brazilian law. Six samples of pulps, seven tropical juices (four unsweetened and three sweetened) and nine nectars (six conventional and three light) were analyzed for soluble solids ( ${ }^{\circ}$ Brix), $\mathrm{pH}$, total acidity and total sugars. Following the parameters set by law, the pulps were also analyzed for total solids concentration and ratio. Among the beverages, all trademarks of tropical juices and nectars showed results consistent with the legislation. However, this didn't occur with the pulps which had a sample with a total sugar value above the maximum allowed, while the other two had values below the minimum total solids. That is, among twenty two samples analyzed, three didn't comply with the determinations of the Brazilian law. This shows that the inadequacy of mango products was restricted to individual cases, representing, in this study, $14 \%$ of the analyzed samples.
\end{abstract}

Key-words: Mangifera indica, physical-chemical analysis, identity and quality standards.

\section{REFERÊNCIAS}

BRANCO, I. G.; GASPARETTO, C. A. Comportamento reológico de misturas de polpa de manga e sucos de laranja e cenoura utilizando Modelo de Casson. Brazilian Journal of Food Technology, Campinas, v. 8, n. 2, p. 183-189, 2005.

BRASIL. Ministério da Agricultura, Pecuária e Abastecimento. Instrução Normativa n. 1, de 7 de janeiro de 2000. Regulamento técnico geral para fixação dos padrões de identidade e qualidade para polpa de fruta. Diário Oficial [da] República Federativa do Brasil, Brasília, DF, 10 de janeiro de 2000 . Disponível em: < http://extranet.agricultura.gov.br/sislegis-consulta/consultarLegislacao.do?operacao=visualizar\&id=7777>. Acesso em: 6/12/2011. 
BRASIL. Ministério da Agricultura, Pecuária e Abastecimento. Instrução Normativa n. 12, de 4 de setembro de 2003. Regulamento técnico para fixação dos padrões de identidade e qualidade gerais para suco tropical e néctar. Diário Oficial [da]República Federativa do Brasil, Brasília, DF, 9 de setembro de 2003. Disponível em: $<$ http://extranet.agricultura.gov.br/sislegis-consulta/consultarLegislacao.do?operacao=visualizar\&id=2831>. Acesso em: $6 / 12 / 2011$.

BRASIL. Ministério da Saúde. Agência Nacional de Vigilância Sanitária. Métodos físico-químicos para análise de alimentos. 4. ed. Brasília, DF: Ministério da Saúde, 2005. 1018 p.

BRASIL. Ministério da Agricultura, Pecuária e Abastecimento. Decreton. 6.871, de 4 de junho de 2009. Regulamenta a Lei n. 8.918, de 14 de julho de 1994, que dispõe sobre a padronização, a classificação, o registro, a inspeção, a produção e a fiscalização de bebidas. Diário Oficial [da] República Federativa do Brasil,Brasília, DF, 5 de junho de 2009. Disponível <http://extranet.agricultura.gov.br/sislegisconsulta/consultarLegislacao.do?operacao=visualizar\&id=20271>. Acesso em: $6 / 12 / 2011$.

CARDELlO, H. M. A. B.; CARDELlO, L. Teor de vitamina C, atividade de ascorbato oxidase e perfil sensorial de manga (Mangifera indica,L.) Var. Haden, durante o amadurecimento. Ciência e Tecnologia de Alimentos, Campinas, v. 18, n. 2, p. 211-217, 1998. http://dx.doi.org/10.1590/S0101-20611998000200013

CHAVES, J. B. P. Noções de microbiologia e conservação de alimentos. Viçosa, MG: Ed. UFV, 1993.

CHITARRA, M. I. F.; CHITARRA, A. B. Pós-colheita de frutas e hortaliças: fisiologia e manuseio. Lavras: ESALFAEPE, 1990. 320 p.

COPERSUCAR. Controle químico da fabricação de açúcar. Cooperativa Central dos Produtores de Açúcar e Álcool do Estado de São Paulo, 1978. 127 p.

FOOD AND AGRICULTURAL ORGANIZATION. Food and agricultural commodities production. 2014. Disponível em: <http://faostat3.fao.org/faostat-gateway/go/to/download/Q/QC/E>. Acesso em: 29 Mar. 2014

INSTITUTO BRASILEIRO DE GEOGRAFIA E ESTATÍSTICA. Censo agropecuário 2012. Disponível em: $<$ http://www.sidra.ibge.gov.br/bda/tabela/

listabl1.asp?c=1613\&n=0\&u=0\&z=\&i=P>. Acesso em: 29 Mar. 2014.

MAGALHÃES, E. F. et al. Estabilidade do suco tropical de manga (Mangifera indica, L.) envasado pelos processos hot fill e asséptico. Revista Ciência Agronômica, Fortaleza, v. 39, n. 1, p. 77-84, 2008.

MANGO. Encyclopedia Britannica Online. 2011. Disponível

em: <http://britannica.com/EBchecked/topic/362003/mango>. Acesso em: 6/12/2011.

OLIVEIRA, A. B. Caracterização físico-química, química e bioquímica do suco tropical de manga (Mangifera indica, L.) não adoçado obtido pelo processo hot fill. Fortaleza, 2006. 110 f. Dissertação (Mestrado em Tecnologia de Alimentos), Centro de Ciências Agrárias, Universidade Federal do Ceará.

PINHEIRO A. M. et al. Avaliação química, físico-química e microbiológica de sucos de frutas integrais: abacaxi, caju e maracujá. Ciência e Tecnologia de Alimentos, Campinas, v. 26, n. 1, p. 98-103, 2006. http://dx.doi.org/10.1590/S0101-20612006000100017

PONTES, M. M. M. Polpa de manga processada por alta pressão hidrostática: aspectos microbiológicos, nutricionais, sensoriais e a percepção do consumidor. Seropédica, 2008. 122 f. Dissertação (Mestrado em Ciência e Tecnologia de Alimentos), Instituto de Tecnologia de Alimentos, Universidade Federal Rural do Rio de Janeiro.

SANTOS, G. M. et al. Parâmetros físico-químicos de sucos tropicais de manga e de goiaba de diferentes marcas comerciais brasileiras. In: REUNIÃO ANUAL DA SBPC, 57., 2005, Fortaleza. Anais... Fortaleza, 2005.

SILVA, R. A. et al. Avaliação físico-química e sensorial de néctares de manga de diferentes marcas comercializadas em Fortaleza/CE. Publication UEPG: Ciências Exatas e da Terra, Agrárias e Engenharias, Ponta Grossa, v. 11, n. 3, p. 21-26, 2005.

SILVA, F. A. S.; AZEVEDO, C. A. V. Principal components analysis in the software assistat-statistical attendance. In: WORLD CONGRESS ON COMPUTERS IN AGRICULTURE, 7., 2009, Reno. Conference Proceedings. St. Joseph: 
American Society of Agricultural and Biological Engineers, 2009. Disponível em: <http://elibrary.asabe.org/azdez.asp?JID=1\&AID=29066\&CID=wcon2009\&T=2>. Acesso em: 31 Mar. 2014.

Submetido em 16 dez. 2013, Aceito para publicação em 11 jan. 2015, Publicado em 10 dez. 2015. 